\title{
Deformation properties of a subgrade in structures reinforced with full displacement piles
}

\author{
Alexey Lanis ${ }^{1}$, Denis Razuvaev ${ }^{1}$, and Petr Lomov $^{1, *}$ \\ ${ }^{1}$ Siberian Transport University, 630049 Novosibirsk, Russia
}

\begin{abstract}
Construction of transport infrastructure facilities on weak subgrades requires special soil improvement measures. One of the advanced methods for deep subgrade soil compaction is known to be Full Displacement Piles (FDP). The purpose of this paper is to establish dependencies of subgrade deformation properties of a soil body reinforced with full displacement piles on reinforcement parameters and soil conditions. Using numerical simulation methods, the authors identified reinforcement parameters and initial soil indicators that have a significant effect on change in the deformation modulus of the reinforced body in the considered boundary conditions. Results of field experimental studies confirmed the reliability of the newly established relationships and regularities.
\end{abstract}

\section{Introduction}

When constructing a roadbed of transport infrastructure facilities in areas where weak clay soils prevail (with a deformation modulus of less than $5 \mathrm{MPa}$ ), including unfrozen subgrades [1], road builders face a problem of significant compressibility of a subgrade under operational loads and weight of facilities. In order to solve this problem and ensure stable operation of facilities, they use various methods to reinforce and compact subgrade soils.

A number of studies are underway to develop new and improve existing methods of soil reinforcement and compaction. They include reinforcement of soils with concrete piles [2, $3,4]$, soil compaction using internal vibratory compactors [5], soil reinforcement by jet grouting $[6,8,10]$, and combined reinforcement methods [13].

Deep compaction by Full Displacement Piles (FDP) is the most interesting method for transport construction [11]. This subgrade soil improvement method has proved to be effective in industrial and civil construction $[11,12]$. The key barrier to wide-scale adoption of this reinforcement method in transport construction is lack of functional dependencies of deformation modulus on soil indicators, which can be used to determine deformation parameters of the reinforced body that are applicable to linear structures and take into account their features.

\footnotetext{
${ }^{*}$ Corresponding author: LomovPO@mail.ru
} 
Subgrades of linear structures, including railways and motorways, are characterized by a wide variety of soil conditions, even within a single construction site. In this connection, theoretical justification and calculation of reinforcement parameters based on available geotechnical data is a highly relevant problem.

Since one of the key performance criteria for roadbeds on a weak subgrade is limited ultimate settlement of a structure, the purpose of this paper can be formulated as follows: to establish dependencies of deformation properties of a reinforced subgrade on FDP reinforcement parameters and initial soil conditions. In order to accomplish this purpose, it is reasonable to use numerical simulation and field experiments based on multivariate analysis of variance using a Latin square design [15]. This approach has proved to be highly effective [13] and can be used to identify, with sufficient accuracy, the reinforcement parameters that have a significant effect on the performance of the structure under study [15].

The novelty of the paper consists in theoretical justification and calculations for the FDP reinforcement method, which are required to select subgrade soil reinforcement parameters for linear transport structures (roadbeds) with initial soil conditions varying with length and, if necessary, a required deformation modulus.

\section{Research methods}

The performance of a subgrade reinforced with full displacement piles was studied by numerical modeling with GTS NX software and full-scale field experiments.

Numerical simulation enables to identify the reinforcement parameters that have a significant effect on the performance of the reinforced body, and establish the critical regularities. The reliability of numerical simulation data can be verified on the basis of field experiments.

A review of studies $[11,12,14]$ shows that the reinforcement parameters that can influence soil reinforcement results include spacing $l$ and diameter of reinforcing members $d$ (hereinafter these parameters will be replaced with a reinforcement coefficient defined as $\xi=d / l$ ), as well as uniaxial compressive strength of pile material $R$. The key parameters that characterize change in initial soil indicators include void ratio $e$ and liquidity index $I_{L}$.

The following varying boundary conditions (hereinafter referred to as the factors) were established for the selected reinforcement parameters and initial soil indicators: reinforcement coefficient -0.25 to 0.50 ; strength of reinforcing member material -0.2 to $1.0 \mathrm{MPa}$; soil liquidity index -0.15 to 0.85 fractions; void ratio -0.650 to 0.850 .

When simulating the performance of the reinforced body, it is important to describe its properties adequately and reliably. A digital model of the reinforced body was constructed on the basis of field experiments, laboratory and theoretical studies [13, 14]. In the digital model, holes for full displacement piles were simulated with a varying diameter. An effective soil compaction zone around the holes was also taken into account.

In the model of a reinforced subgrade fragment, deformation modulus $\mathrm{E}$ was taken as an indicator of change in deformation properties of the body.

In order to estimate the compressibility of reinforced bodies and determine regularities of change in the deformation modulus, static load tests with a flat round plate were simulated in the digital model (Fig. 1). 


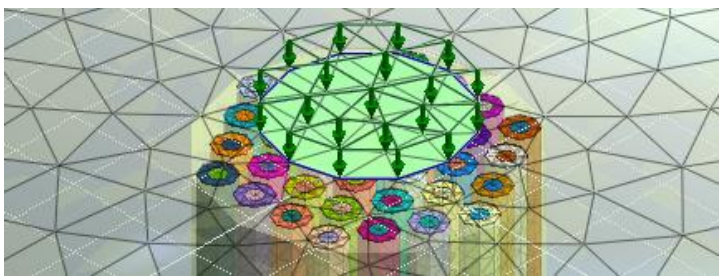

Fig. 1. The digital model of the body reinforced $(\xi=0.5)$ with full displacement piles, and of the plate, built with the GTS NX software.

Field experimental studies of the reinforced bodies were conducted on experimental sites. The reinforced bodies were constructed with a GRO-250 soil compaction tool (Fig. 2 a) for soils with a liquidity index $I_{L}<0.5$.

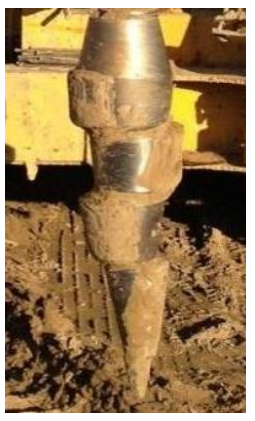

a

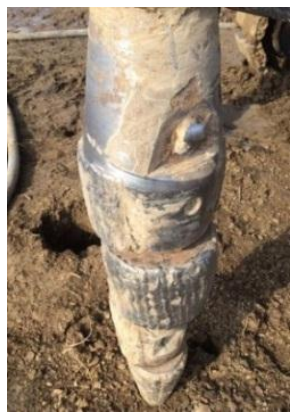

b

Fig. 2. Displacement tools used to prepare experimental sites: $a$-GRO-250; $b$ - displacement machine designed according to the RF Patent No. 147223.

For soils with a liquidity index $I_{L}>0.5$, a special displacement machine with a hollow shaft (Fig. 2 b) was used. It was designed by the authors according to the RF Patent No. 147223 to fill holes with a grout, while lifting the displacement tool.

In order to study the compressibility of the soil bodies reinforced with full displacement piles, the authors used a flat round plate with an area of $5,000 \mathrm{~cm}^{2}$, as shown in Figure 3.

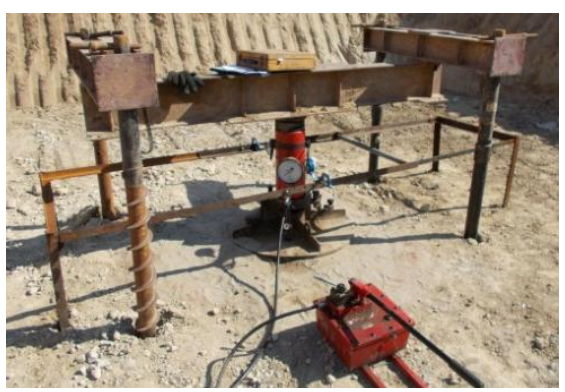

Fig. 3. Flat round plate with an area of $5,000 \mathrm{~cm}^{2}$.

Based on the results of numerical simulation and field experiments, the authors performed a correlation analysis to assess the reliability of the collected data. 


\section{Results of simulation and field experiments}

The results of numerical simulation show that full displacement piles take up a major part of the stresses arising from plate loading. The highest stress release rate is observed at a depth of 2...2.5 times the diameter of the plate.

Vertical displacement diagrams for reference points of the digital model were used to determine the compressibility of the test fragment of the reinforced body at the subgrade (Fig. 4)

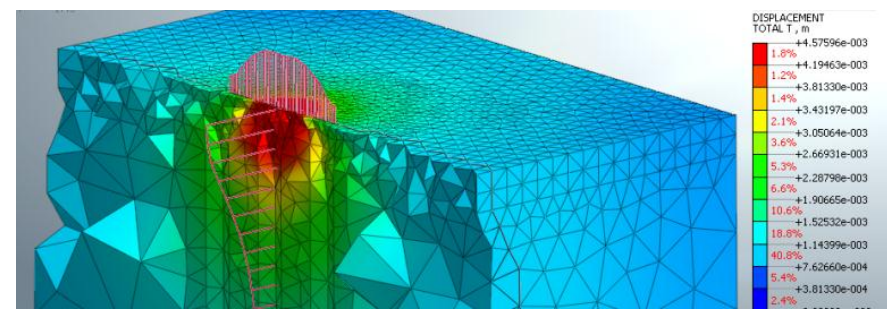

Fig. 4. Vertical displacement diagrams for reference points of the soil body reinforced with full displacement piles, in a plan view and in depth.

The vertical displacement diagrams for reference points were used to determine the deformation modulus of the reinforced body.

The analysis of the numerical simulation results shows that the effectiveness of soil reinforcement with full displacement piles depends directly on the reinforcement parameters and initial soil indicators. By relying on the obtained data, the authors assessed the influence and significance of individual factors on the performance of the reinforced body using an F-test according to the algorithm described in [15].

In soils with a liquidity index $\mathrm{I}_{\mathrm{L}}$ of 0.45 to 0.85 fractions, the greatest effect of reinforcement can be achieved mainly by reducing reinforcement spacing and increasing the diameter of holes. The statistically processed results of numerical simulation are presented in Figure 5 as dependencies that reflect the influence of factors on the compressibility of the body.

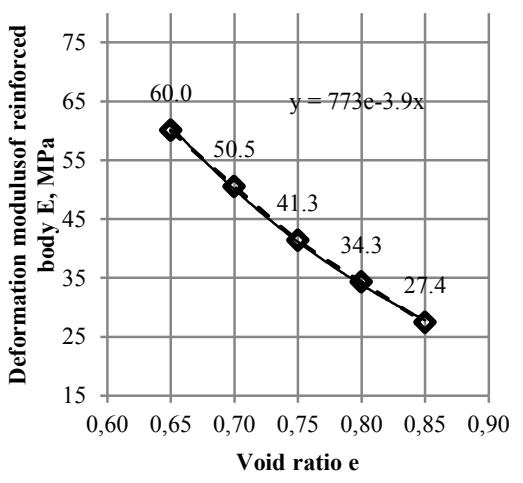

a

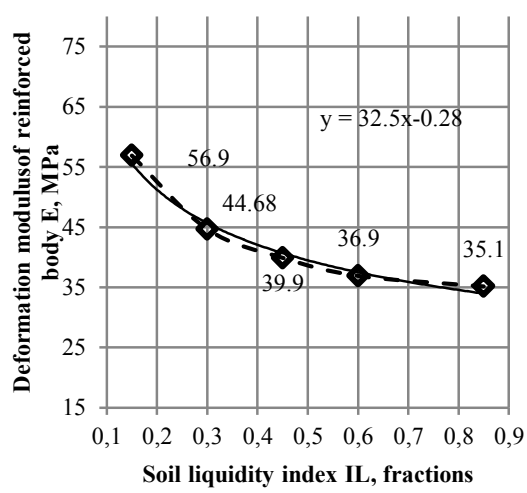

b 


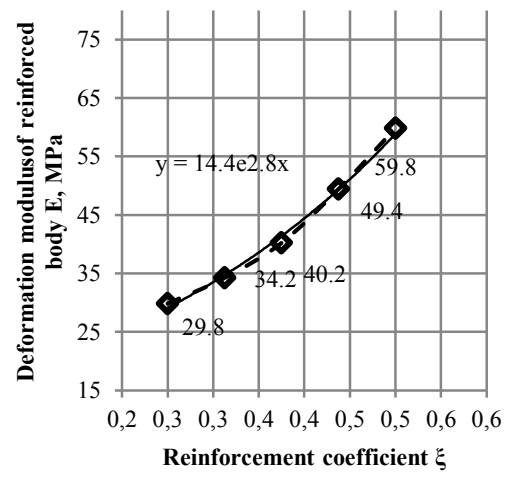

$\mathrm{C}$

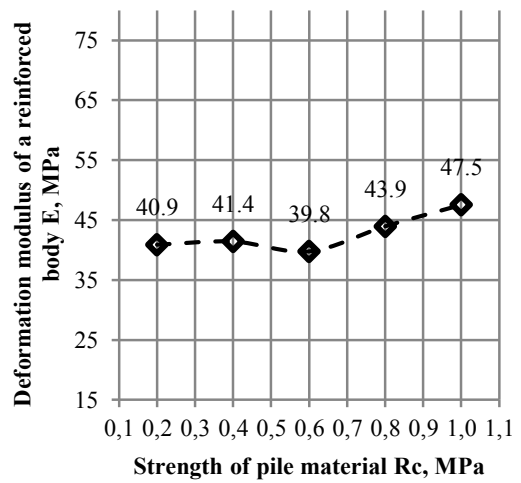

d

Fig. 5. The dependencies that reflect the influence of reinforcement parameters and initial soil indicators on the deformation modulus of the body reinforced with full displacement piles: $\mathrm{a}-$ on void ratio; $\mathrm{b}$ - on liquidity index; $\mathrm{c}$ - on reinforcement coefficient; $\mathrm{d}$ - on pile material.

The F-test values [15] for the studied factors are given in Table 1. Using the obtained values, it is possible to determine the significant factors as follows: the factors whose test values exceed the critical value (for the purpose of this study $F_{c r}=3.2592$ ) do not correlate with a mean of the sampled population and are significant for the tested mathematical model.

Table 1. F-test value.

\begin{tabular}{|l|c|c|}
\hline \multirow{2}{*}{ Factor } & \multicolumn{2}{|c|}{ F-test value } \\
\cline { 2 - 2 } & Actual, for E & Critical \\
\hline Reinforcement coefficient & 25.238 & \multirow{2}{*}{3.2592} \\
\hline Void ratio & 28.963 & \\
\hline Liquidity index & 13.167 & \\
\hline $\begin{array}{l}\text { Material of full displacement piles } \\
\text { (strength) }\end{array}$ & 1.662 & \\
\hline
\end{tabular}

By analyzing the obtained dependencies (Fig. 5) and F-test values (Table 1), we can conclude that soil conditions have a lesser effect on the compressibility of the reinforced body than spacing and diameter of full displacement piles. The strength of pile material has an insignificant effect as compared to other factors. Soil reinforcement by full displacement piles in soils with a liquidity index $I_{L}$ exceeding 0.5 fractions is less effective. In such soil conditions, the greatest effect is achieved by reducing spacing and increasing diameter of piles. Three of the four studied factors contributed most to change in the deformation modulus of the reinforced body.

In order to use the results of numerical simulation in theoretical justification and calculation of reinforcement parameters for subgrade soils reinforced with full displacement piles, characteristic curves were plotted (Figs. 6 and 7). 


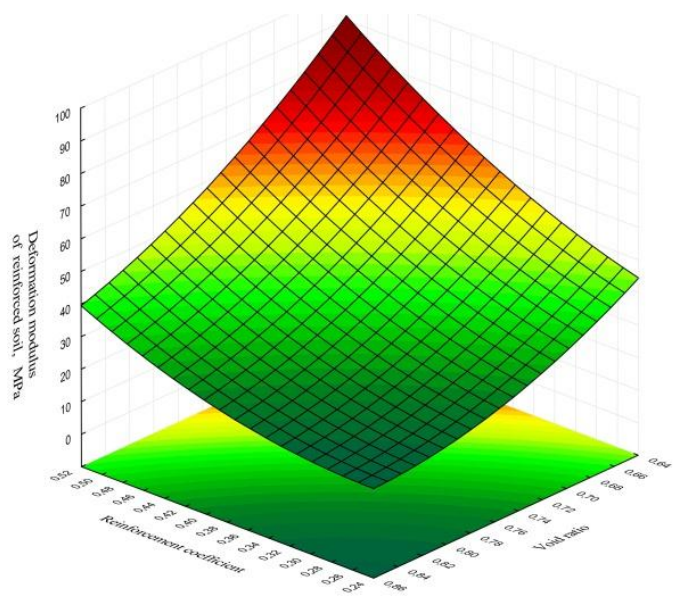

Fig. 6. Deformation modulus of the body reinforced with full displacement piles as a function of the reinforcement coefficient and initial void ratio.

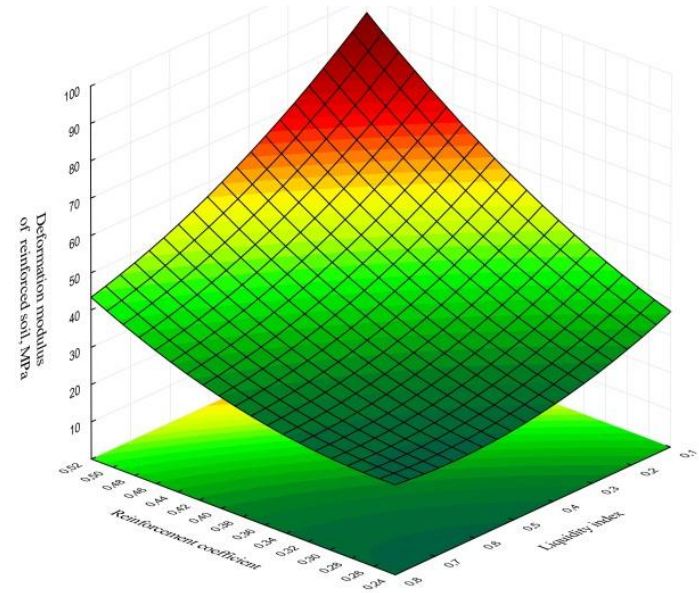

Fig. 7. Deformation modulus of the body reinforced with full displacement piles as a function of the reinforcement coefficient and initial soil liquidity index.

The results of field experiments are graphically represented in Figure 8 as dependencies that reflect the influence of reinforcement parameters and initial soil indicators on the deformation modulus of the reinforced body. 


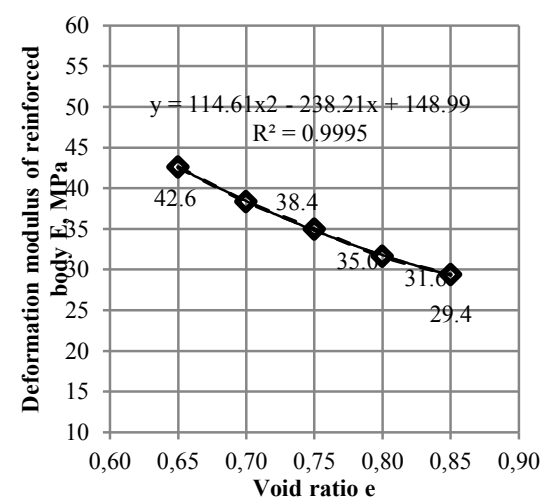

a

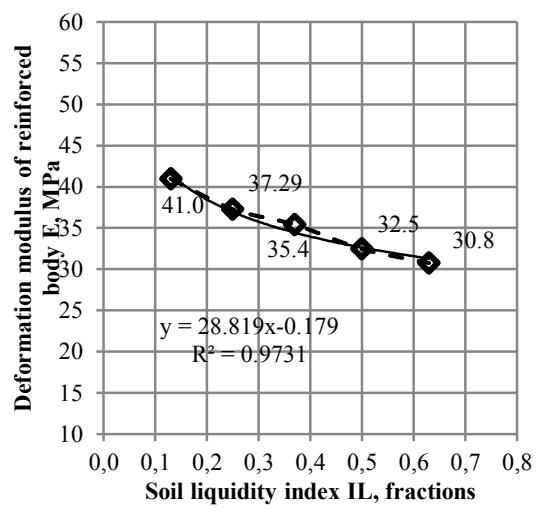

b

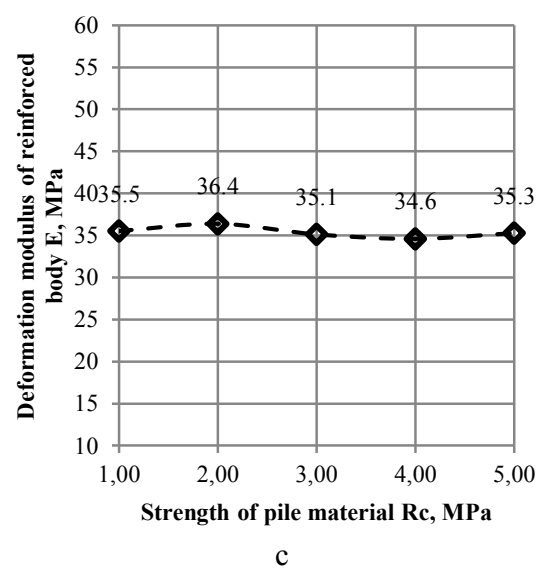

Fig. 8. Dependencies that reflect the influence of reinforcement parameters and initial soil indicators on the deformation modulus of the reinforced body, based on field experiments (at $\xi=0.25$ ): $\mathrm{a}$ - on void ratio; b - on liquidity index; $\mathrm{c}$ - on pile material.

The adequacy of digital models and correlation of numerical simulation data and experimental studies was assessed by the F-test. When performing a correlation analysis of the findings for soil reinforcement with full displacement piles, the authors considered sampled populations of deformations modules of the reinforced bodies, which were experimentally obtained and determined from the dependences shown in Figures 6 and 7 for the reinforcement coefficient $\xi=0.25$ (at which all the experimental studies were conducted).

According to the correlation analysis, the F-test value for the deformation modulus $\mathrm{E}$ is equal to 1.314 at the critical value $\mathrm{F}_{\mathrm{u}}=1.984$. This suggests that the comparability of the results with the previously determined dependencies reaches $95 \%$.

\section{Conclusion}

The performed studies of the full displacement piles (FDP) method allowed the authors to identify significant reinforcement parameters and establish functional dependencies of changes in deformation properties of the soil body reinforced with full displacement piles. 
The obtained findings can be used to design reinforcements of subgrades with full displacement piles for linear transport structures with ground conditions varying with length and, if necessary, a required deformation modulus.

Further studies for developing the FDP method should be aimed at determining strength properties of a soil body reinforced with full displacement piles.

\section{References}

1. A.L. Lanis, D.A. Razuvaev, Sciences in Cold and Arid Regions, 9(3), 205-212 (2017).

2. T. Tronda, Proceedings of the International Conference on Deep Foundations, Seepage Control and Remediation, Deep Foundations, 225-231 (2016).

3. T. Tronda, Proceedings of the 8AYGEC, 155-158 (2016).

4. R.K. Kar, P.K. Pradhan, A. Naik, Electronic J. of Geotech., 17, 3861-3874 (2012).

5. J. Grabe, E. Heins, T. Hamann, Sixth International Geotechnical Symposium on Disaster Mitigation in Special Geoenvironmental Conditions, 281-284 (2015).

6. K.M. Rollins, M. Herbst, M. Adsero, D. Brown, Advances in Analysis, Modeling \& Design, Proceedings... ASCE, 1563-1572 (2010).

7. S.A. Tan, S. Tjahyono, K.K. Oo, Journal of Geotechnical and Geoenvironmental Engineering, 134, 185-194 (2008).

8. J. Stacho, 16th International conference of $\mathrm{PhD}$ students with international participation, 1-8 (VUT in Brno, Czech Republic, 2014).

9. A.L. Gotman, M.N. Kharmatulin, SM\&FE, 4, 16-19 (2012).

10. G. Modoni, J. Bzowka, ASCE, 12, 1442-1454 (2012).

11. A.N. Saurin, Papers of the International seminar on soil engineering, foundation engineering and transport works, 236-239 (2000). (in Russian)

12. A.L. Lanis, D.A. Razuvaev, P.O. Lomov, Vestnik SibADI, 2 (48), 110-120 (2016). (in Russian)

13. S.A. Ovchinnikov, Thesis of Candidate of technical sciences, Siberian Transport University, 2014. (in Russian)

14. A.L. Lanis, D.A. Razuvaev, P.O. Lomov, V.S. Vorobyev, News of higher educational institutions. Construction, 9 (705), 31-40 (2017). (in Russian)

15. K. Hartman, E. Letskiy, V. Shefer, Planirovanie jeksperimentov $v$ issledovanii tehnologicheskih processov [Experiments planning in the study of technological processes] (Mir Publ., Moscow, 1977). (in Russian) 